\title{
TRANSFORMATION OF THE RUSSIAN LABOR MARKET IN THE CONTEXT OF THE PANDEMIC: KEY ISSUES AND TRENDS
}

\author{
Maria F. Mizintseva \\ All-Russian Institute of Scientific and Technical Information of the Russian Academy of Sciences, \\ Moscow, Russian Federation \\ Anna R. Sardarian \\ All-Russian Institute of Scientific and Technical Information of the Russian Academy of Sciences, \\ Moscow, Russian Federation
}

\begin{abstract}
The article discusses the main problems and trends in the labor market in the context of pandemics using the example of the COVID-2019 virus pandemic. The most typical consequences of the pandemic and its impact on the labor market are identified, including the growth of unemployment, the decline in employment, mass layoffs of workers, and the structural transformation of the labor market. The industries most and least affected by the COVID-2019 pandemic are highlighted. It is emphasized that the most important direction in the transformation of the domestic labor market will be digitalization, which was triggered by the global pandemic in 2020. Among the key areas in the labor market in the field of digitalization, remote forms of work and the emergence and development of new "digital" professions were highlighted. It was revealed that during the months of quarantine measures adopted in the Russian Federation, the number of vacancies in "digital" professions increased on job search websites, including specialists in contextual advertising, targetologists, administrators of online schools, SMM managers, copywriters, and personal online assistants. The analysis of the average level of remuneration of employees of "digital" professions in Russia is carried out. It is concluded that such a transformation of the labor market will require labor resources to acquire fundamentally new skills and competencies, as well as readiness for continuous training. The article uses general scientific methods of $\overrightarrow{7}$ analysis and synthesis, generalization, classification, the method of system analysis, the statistical method of ते studying economic processes, and information analysis.

Key words: labor market, COVID-2019 pandemic, digital labor market, pandemic economy, digital economy, "digital" professions.

Citation. Mizintseva M.F., Sardarian A.R. Transformation of the Russian Labor Market in the Context of the Pandemic: Key Issues and Trends. Vestnik Volgogradskogo gosudarstvennogo universiteta. Ekonomika [Journal of Volgograd State University. Economics], 2021, vol. 23, no. 1, pp. 102-109. (in Russian). DOI: https://doi.org/ $\theta$ í 10.15688/ek.jvolsu.2021.1.8
\end{abstract}




\title{
ТРАНСФОРМАЦИЯ РОССИЙСКОГО РЫНКА ТРУДА В УСЛОВИЯХ ПАНДЕМИИ: ОСНОВНЫЕ ПРОБЛЕМЫ И ТЕНДЕНЦИИ
}

\author{
Мария Федоровна Мизинцева \\ Всероссийский институт научной и технической информации РАН, \\ г. Москва, Российская Федерация \\ Анна Романовна Сардарян \\ Всероссийский институт научной и технической информации РАН, \\ г. Москва, Российская Федерация
}

\begin{abstract}
Аннотация. В статье рассматриваются основные проблемы и тенденции на рынке труда в условиях пандемий на примере пандемии вируса COVID-2019. Выявлены наиболее типичные последствия пандемии и ее влияние на рынок труда, в том числе рост безработицы, снижение занятости населения, массовые сокращения работников, структурная трансформация рынка труда. Выделены отрасли, наиболее и наименее пострадавшие от пандемии COVID-2019. Подчеркивается, что важнейшим направлением в трансформации отечественного рынка труда станет цифровизация, толчок которой дала мировая пандемия в 2020 году. Среди ключевых направлений на рынке труда в области цифровизации были выделены дистанционные формы работы и появление и развитие новых «цифровых» профессий. Выявлено, что за месяцы карантинных мероприятий, принятых в Российской Федерации, на сайтах по поиску работы увеличилось количество ряда вакансий по «цифровым» профессиям, в том числе специалиста по контекстной рекламе, таргетолога, администратора онлайн-школ, SMM-менеджера, копирайтера, личного онлайн-помощника. Проведен анализ среднего уровня оплаты труда работников «цифровых» профессий в России. Сделан вывод о том, что подобная трансформация рынка труда потребует от трудовых ресурсов приобретения принципиально новых навыков и компетенций, а также готовность к постоянному обучению. В статье применялись общенаучные методы анализа и синтеза, обобщения, классификации, метод системного анализа, статистический метод исследования экономических процессов, информационный анализ.
\end{abstract}

Ключевые слова: рынок труда, пандемия COVID-2019, цифровой рынок труда, экономика пандемий, цифровая экономика, «цифровые» профессии.

Цитирование. Мизинцева М. Ф., Сардарян А. Р. Трансформация российского рынка труда в условиях пандемии: основные проблемы и тенденции // Вестник Волгоградского государственного университета. Экономика. -2021. - Т. 23, № 1. - C. 102-109. - DOI: https://doi.org/10.15688/ek.jvolsu.2021.1.8

\section{Введение}

В первом полугодии 2020 г. мир столкнулся с беспрецедентной глобальной угрозой, чему способствовало развитие пандемии нового коронавируса COVID-2019. Эта пандемия привела к серьезным экономическим, социальным, технологическим, производственным и иным последствиям. Сложившаяся ситуация обусловила актуальность исследований широкого круга вопросов в области экономики пандемий, в том числе вопросов трансформации на современном рынке труда. Однако к сегодняшнему дню аспектам функционирования рынка труда в подобных условиях посвящены лишь единицы работ, большинство из которых охватыва- ет более широкие направления. Среди наиболее интересных исследований, которые были опубликованы за последний период, нами выделены работы таких авторов, как: В.О. Анисимов [Анисимов, 2020], Б.А. Биняминов [Биняминов, 2020], А.Е. Кравченко [Кравченко, 2020], А.Н. Лейбович [Лейбович, 2020], Р.А. Пупышева, Ф.Ф. Ситдиков [Пупышева и др., 2020], М.Л. Силкина [Силкина, 2020], С.С. Солдатова, В.В. Солдатова [Солдатова и др., 2020]. Также следует отметить, что незадолго до развивающейся пандемии ряд авторов уже обращали внимание на актуальность принципиальных изменений на рынке труда. Среди этих авторов можно назвать А.Л. Попову, М.В. Канавцева [Попова и др., 
2018], С. Кергроуча [Кергроуч, 2017], А.В. Родионова, О.Ю. Родионову [Rodionov et al., 2019] и др.

В мае 2020 г. сотрудниками Всероссийского института научной и технической информации Российской академии наук (ВИНИТИ РАН) был представлен сборник по результатам анализа научной информации по новому коронавирусу 2019 г. (SARS-CoV-2) и пандемии COVID-2019, который включил в себя биологические, медицинские и социально-экономические аспекты, в том числе: информацию о глобальных эпидемиологических угрозах последнего столетия, последствиях пандемий в отдельных секторах экономики, влиянии распространения COVID-19 на здравоохранение и фармацевтическую отрасль, туризм и авиаперевозки, агропромышленный комплекс, автомобильную промышленность, электронную промышленность, энергетику, машиностроение, металлургию, строительство и др. [Пандемия COVID-2019, 2020].

Тем не менее подобных работ, в том числе исследований по особенностям функционирования рынка труда в условиях пандемий, в научной периодике еще недостаточно. Представлены единицы публикаций по тенденциям на рынке труда в условиях пандемий, проблемам спроса и предложения, а также путям оперативного решения этих проблем, что подчеркивает актуальность темы настоящего исследования.

\section{Влияние пандемии}

\section{на сферы экономики и рынок труда}

Во многих странах мира, наиболее сильно затронутых пандемией, уже сегодня наблюдается серьезный спад производства, снижение темпов роста экономики, снижение уровня благосостояния граждан, нестабильные тенденции на рынке труда. Так, особенно заметны сегодня рост безработицы, снижение занятости населения, массовые сокращения работников, структурные трансформации на рынке труда, которые произошли в ряде стран мира. Сильнее всего пострадали работники таких отраслей экономики, как транспорт, туризм, сфера обслуживания (парикмахерские, фитнес-центры), культура (театры, кинотеатры и пр.). С другой стороны, можно наблюдать тенденцию активизации таких направле- ний, как производство и продажа медицинских препаратов и товаров, оказание дистанционных медицинских услуг, онлайн-образование, доставка продуктов питания и предметов первой необходимости и пр.

По оценкам Euler Hermes, общая потеря рабочих мест в США по итогам прошедшего года может составить более 4 млн, а в странах EC - 1,5 млн рабочих мест. Ожидается, что уровень официальной безработицы в США увеличится как минимум на $3 \%$ и достигнет $6,5 \%$ в середине 2021 г., а в ЕС - до $8 \%$ [COVID-19: Quarantined Economics, 2020]. По России подобные прогнозы сильно разнятся. Однако, если учесть, что в последние годы уровень официальной безработицы был в районе 4,5-5\%, то увеличится она, по нашим оценкам, как минимум до европейского уровня и составит 7,5-8 \%. Причем больше всего последствия пандемии отразятся на таких работниках, как: работники учреждений общественного питания, менеджеры по туризму, а также значительная часть самозанятых. Напротив, рост занятости может ожидаться в сфере торговли продуктами питания, дистанционного образования, курьерской доставки. Рост занятости в ближайший год может наблюдаться в онлайн-секторе отечественного рынка труда.

\section{Переход на дистанционный формат занятости}

Условия, в которых оказалась Россия при пандемии COVID-2019, серьезно трансформировали рынок труда, на котором активизировалось направление онлайн-занятости. Данный формат труда не нов и активно развивался в последнее десятилетие, особенно в ведущих странах мира. Так, по данным Всемирной организации труда, количество удаленных работников в мире до пандемии составляло $17 \%$, а в Японии и США достигало почти $40 \%$ [MOT, 2020].

В развивающихся странах доля дистанционной занятости на рынке труда не была столь значительной, однако сегодня подобный формат продемонстрировал серьезные преимущества, которые оценили миллионы трудовых ресурсов по всему миру. По прогнозу Глобального института McKinsey, к 2036 г. 
может быть автоматизировано до 50 \% работы, а к 2066 г. эта доля может достичь от 46 до $99 \%$ [McKinsey, 2020].

Если ранее дистанционно преимущественно трудились представители определенных сфер экономики (работники IT-сферы, дистанционного образования, call-центры), то сегодня наметилась тенденция расширения перечня отраслей, которые также могут предоставить формат онлайн-занятости для части своих сотрудников.

Развитие пандемии в текущем году наметило на рынке труда еще одну тенденцию, которая заключается в расширении доступности рынка труда отдельным категориям граждан, преимущественно за счет дистанционной занятости - лицам с ограниченными физическими возможностями; матерям-одиночкам с маленькими детьми; пенсионерам; жителям отдаленных регионов страны, в том числе из сельской местности. Рост предложений по дистанционной работе расширил возможности трудовой занятости для перечисленных выше категорий граждан и, таким образом, повысил для них уровень открытости рынка труда. Это, в свою очередь, послужило трансформации среднестатистического портрета работника на рынке труда. Так, снизились требования к возрасту, физической мобильности, полу и пр. Вместе с этим выросли требования к уровню новых навыков и компетенций в области дистанционных форматов занятости, готовность к непрерывному обучению, гибкость мышления, высокие коммуникативные навыки.

\section{Основные требования работников в условиях пандемии}

В условиях, сложившихся в последние месяцы по всему миру, на рынке труда изменились и типичные требования работников к занимаемой должности. Важнейшим оказался не уровень заработных плат и возможность карьерного роста, а социальная ответственность бизнеса перед работником. Так, при массовых сокращениях персонала во многих компаниях на российском рынке были также организации, где сотрудников перевели на неполную занятость, но обеспечили всем минимальный уровень оплаты труда. Кроме того, даже при отмене ограничительных мер и во- зобновлении хозяйственной деятельности российских компаний, которые так или иначе пострадали от последствий пандемии, чтобы не увольнять часть сотрудников работодатели предлагали им перейти на иные формы занятости: частичную или дистанционную, уменьшая при этом оплату труда, но сохраняя за работником часть ставки. Следует подчеркнуть, что с повышением доверия к дистанционной занятости, сегодня все большее количество работников готовы перейти на удаленную работу, даже теряя при этом часть заработной платы. Причем, если в последние годы эта тенденция была видна, как правило, среди молодежи, сегодня на подобный формат занятости готовы перейти и лица более старшего возраста.

\section{Развитие «цифровых» профессий на рынке труда}

Трансформация рынка труда и его изменение в сторону активного развития «цифровых» профессий начали происходить и до развития пандемии COVID-2019, однако сложившаяся ситуация только усилила цифровые тенденции на рынке труда. В условиях пандемии, когда во многих странах мира были приняты карантинные меры, многие сотрудники остались без работы или же были переведены на дистанционные модели труда. Оказалось, что ряд профессий может успешно функционировать в таком формате и обходиться компании с меньшими финансовыми и организационными затратами. Так, например, на сайтах предложений о работе с марта 2020 г. можно было наблюдать увеличение вакансий личного помощника-онлайн, заработная плата которого на российском рынке труда составляла от 20 тыс. рублей. В обязанности такого работника входит выполнение ежедневных поручений руководителя, осуществление необходимых звонков, координация выполнения рабочего графика начальника. Активизация «цифровых» профессий, как было отмечено, открывает широкие возможности для жителей регионов с низким уровнем оплаты труда, в том числе жителей сельской местности, лиц с ограниченными физическими возможностями, женщин в декрете, матерей-одиночек с маленькими детьми. 
Кроме того, на рынке труда можно наблюдать тенденцию расширения перечня дистанционных профессий. Так, к примеру, за последний год на специализированных сайтах по поиску работы увеличилось количество вакансий специалиста по контекстной рекламе, таргетолога, администратора онлайн-школ, SMM-менеджера, копирайтера, личного онлайн-помощника и др. Причем уровень заработных плат таких специалистов не уступает заработным платам работающих в офлайнофисах. Так, например, оплата труда специалиста по контекстной рекламе составляет в среднем 55-70 тыс. руб.; таргетолога - 4580 тыс. руб.; SММ-менеджера -60-80 тыс. руб. и проч. (см. таблицу).

\section{Краткосрочная занятость в условиях пандемии}

В качестве еще одной особенности на рынке труда в условиях пандемии можно выделить краткосрочную занятость. Так, в апреле - мае 2020 г. на отечественном рынке труда был зафиксирован стремительный рост вакансий курьеров, водителей-экспедиторов, сотрудников call-центров. Это связано с тем, что в условиях карантинных мер многие торговые сети перешли на онлайн-работу и им потребовалось значительное расширение штата, в том числе водителей и курьеров. Например, серьезно расширили онлайн доставку крупные торговые сети и ритейлеры (крупнейший отечественный ритейлер X5 Retail Group зафиксировал увеличение интер- нет-продаж на 40 \% в мае 2020 г. по сравнению с апрелем того же года) [X5 Retail Group, 2020]. И хотя с отменой карантинных мер в ряде регионов России в июне 2020 г. интернет-продажи сократились, тем не менее, это позволило поддержать в течение нескольких месяцев граждан, ранее потерявших работу из-за сокращений. Несмотря на то что торговым сетям потребовалось серьезное увеличение числа некоторых должностей, а с отменой ограничений часть этих сотрудников были уволены, тем не менее, эксперты прогнозируют рост интернет-формата торговли в дальнейшем, и, таким образом, рост краткосрочной занятости на определенные периоды в течение года.

Среди краткосрочных проектов также можно отметить работу в волонтерских организациях, в качестве медицинских консультантов, социальных работников, личных онлайн-помощников, которых нанимали на время ограничительных мероприятий, связанных с пандемией.

\section{Заключение}

На отечественном рынке труда в последние десятилетия произошли серьезные количественные и качественные преобразования, в том числе сокращение занятости в производственных отраслях, увеличение среднего возраста работников, повышение уровня навыков и компетенций сотрудников. Серьезные изменения наметились и в связи с начавшейся пандемией вируса COVID-2019.

\section{Уровень заработных плат специалистов «цифровых» профессий (на конец мая 2020 г.)}

\begin{tabular}{|l|c|c|c|c|}
\hline \multicolumn{1}{|c|}{ Специальность } & JobLab.ru & Headhunter.ru & Rabota.ru & Superjob.ru \\
\hline Специалист по контекстной рекламе & 60000 & 70000 & 55000 & 57000 \\
\hline Таргетолог & 60000 & 80000 & - & 45000 \\
\hline Мастер комплексного трафика & - & 95000 & - & 50000 \\
\hline Интернет-маркетолог & 60000 & 95000 & 60000 & 50000 \\
\hline Тильдолог & 50000 & - & - & - \\
\hline SММ-менеджер & 65000 & 80000 & 60000 & 75000 \\
\hline Администратор онлайн-школ & - & 22000 & - & - \\
\hline Дизайнер & 80000 & 60000 & 60000 & 60000 \\
\hline Копирайтер & 35000 & 50000 & 55000 & 55000 \\
\hline Vіdео-такег или & 40000 & 50000 & - & 30000 \\
\hline Личный онлайн-помощник & - & 20000 & - & - \\
\hline
\end{tabular}

Примечание. Составлено по: [JobLab.ru; Headhunter.ru; Rabota.ru; Superjob.ru]. 
В сложившихся условиях становится все более очевидным, что отечественный рынок труда претерпевает серьезные изменения, которые в ближайший год будут только усиливаться. В первую очередь рынок труда столкнется с необходимостью и дальнейших преобразований в области структуры рынка, спроса и предложения по ряду профессий, появления совершенно новых профессий, а также рядом проблем, которые потребуют оперативного решения со стороны государства и бизнеса. Кроме того, необходимым станет адаптация современных работников к изменяющимся условиям, приобретение ими новых навыков и компетенций, в том числе в области дистанционных форматов занятости, а также готовность к непрерывному обучению.

\section{СПИСОК ЛИТЕРАТУРЫ}

Анисимов, В. О. Антикризисные меры на рынке труда в условиях пандемии / В. О. Анисимов // Экономика, управление и право в современных условиях : межвуз. сб. ст. - Тольятти, 2020. - С. 15-20.

Биняминов, Б. А. Тренды и перспективы «ухода» бизнеса в режим online: антикризисная мера для российского предпринимательства / Б. А. Биняминов // Modern Economy Success. - 2020. - № 2. - C. 211-217.

Кергроуч, С. Индустрия 4.0: новые вызовы и возможности для рынка труда / С. Кергроуч // Форсайт. - 2017. - Т. 11, № 4. - С. 6-8. Электрон. текстовые дан. - Режим доступа: https://foresight-journal.hse.ru/data/2017/12/24/ $1159810745 / 0-\% \mathrm{D} 0 \% 9 \mathrm{~A} \% \mathrm{D} 0 \% \mathrm{~B} 5 \% \mathrm{D} 1 \% 80 \%$ D0\%B3\%D1\%80\%D0\%BE\%D1\%83\%D1\%876-8.pdf(дата обращения: 12.11.2020). - Загл. с экрана.

Кравченко, А. Е. Как повлияет пандемия 2020 года на экономику и рынок труда в России / А. Е. Кравченко // Использование инновационных технологий в разработке и реализации экономических реформ : сб. ст. Междунар. науч.-практ. конф. - Магнитогорск, 2020. - С. 68-70.

Лейбович, A. H. COVID-19 и рынок труда: старые подходы не работают / А. Н. Лейбович // Стандарты и качество. - 2020. - № 5. - С. 68-70.

MOT : офиц. сайт Международной организации труда (МОТ). - 2020. - Электрон. текстовые дан. - Режим доступа: https:/www.ilo.org/ global/lang —en/index.htm (дата обращения: 14.11.2020). - Загл. с экрана.
Пандемия COVID-2019. Биология и экономика. Специальный выпуск : информ.-аналит. сб. / под ред. д-ра экон. наук М. Ф. Мизинцевой. - М. : Перо, 2020. - 110 c.

Попова, А. Л. Трансформация российского рынка труда в условиях цифровизации экономики / А. Л. Попова, М. В. Канавцев // Известия СанктПетербургского государственного аграрного университета. - 2018. - Электрон. текстовые дан. - Режим доступа: https:/cyberleninka.ru/ article/n/transformatsiya-rossiyskogo-rynkatruda-v-usloviyah-tsifrovizatsii-ekonomiki (дата обращения: 14.11.2020). - Загл. с экрана.

Пупышева, Р. А. Охрана труда в условиях пандемии / Р. А. Пупышева, Ф. Ф. Ситдиков // Студенческий вестник. - 2020. - № 18 (116). - С. 11-13.

Силкина, М. Л. Проблемы российского рынка труда в условиях пандемии / М. Л. Силкина // Современные тенденции и технологии развития потенциала регионов : сб. ст. І Национальной науч.-практ. конф., г. Санкт-Петербург, 24 апр. 2020 г.-СПб. : Изд-во С.-Петерб. ун-та технологий управления и экономики, 2020. - С. 117-119.

Солдатова, С. С. Российский рынок труда в условиях нарастания экономического кризиса вследствие пандемии / С. С. Солдатова, В. В. Солдатова // Научно-образовательный журнал StudNet. - 2020. - № 2. - C. 424- 428.

COVID-19: Quarantined Economics. - Electronic text data. Mode of access: https//www. eulerhermes.com/ en_global/economicresearch/insights/covid-19quarantined-economics.html (date of access: 15.11.2020). - Title from screen.

Headhunter.ru : офиц. сайт портала. - Электрон. текстовые дан. - Режим доступа: www.hh.ru (дата обращения: 15.11.2020). - Загл. с экрана.

JobLab.ru : офиц. сайт портала. - Электрон. текстовые дан. - Режим доступа: www.joblab.ru (дата обращения: 15.11.2020). - Загл. с экрана.

McKinsey: офиц. сайт международной консалтинговой компании. - 2020. - Электрон. текстовые дан. - Режим доступа: https://www.mckinsey.com/ mgi/overview (дата обращения: 15.11.2020). Загл. с экрана.

Rabota.ru : офиц. сайт портала. - Электрон. текстовые дан. - Режим доступа: www.rabota.ru (дата обращения: 16.11.2020). - Загл. с экрана.

Rodionov, A. V. The Role of Personnel Potential in the Development of the Labor Market /A. V. Rodionov, O. Yu. Rodionova // Общество, экономика, управление. - 2019. - Электрон. текстовые дан. Режим доступа: https://cyberleninka.ru/article/n/ the-role-of-personnel-potential-in-thedevelopmentof-the-labor-market/viewer (дата обращения: 16.11.2020). - Загл. с экрана. 
Superjob.ru : офиц. сайт портала. - Электрон. текстовые дан. - Режим доступа: superjob.ru (дата обращения: 16.11.2020). - Загл. с экрана.

X5 Retail Group : офиц. сайт. - 2020. - Электрон. текстовые дан. - Режим доступа: https://www. x5.ru/ru/Pages/Media/News/040620-online.aspx (дата обращения: 15.11.2020). - Загл. с экрана.

\section{REFERENCES}

Anisimov V.O. Antikrizisnye mery na rynke truda v usloviyah pandemii [Anti-Crisis Measures in the Labor Market in the Context of the Pandemic]. Ekonomika, upravlenie i pravo $v$ sovremennyh usloviyah: mezhvuz. sb. st. [Interuniversity Collection of Articles "Economics, Management and Law in Modern Conditions"]. Tolyatti, 2020, pp. 15-20.

Binyaminov B.A. Trendy i perspektivy «uhoda» biznesa $v$ rezhim online: antikrizisnaya mera dlya rossijskogo predprinimatel'stva [Trends and Prospects of "Leaving" Business in the Online Mode: Anti-Crisis Measure for Russian Entrepreneurship]. Modern Economy Success, 2020, no. 2, pp. 211-217.

Kergrouch S. Industriya 4.0: novye vyzovy i vozmozhnosti dlya rynka truda [Industry 4.0: New Challenges and Opportunities for the Labor Market]. Forsajt [Forsite], 2017, vol. 11, no. 4, pp. 6-8. URL: https://foresight-journal.hse.ru/ data/2017/12/24/1159810745/0-\%D0\% 9A $\%$ D0\%B5\%D $1 \% 80 \%$ D0\%B3\%D $1 \% 80$ $\% \mathrm{D} 0 \% \mathrm{BE} \% \mathrm{D} 1 \% 83 \% \mathrm{D} 1 \% 87-6-8 . p d f($ accessed 12 November 2020).

Kravchenko A.E. Kak povliyaet pandemiya 2020 goda na ekonomiku i rynok truda v Rossii [How the 2020 Pandemic Will Affect the Economy and the Labor Market in Russia]. Ispol'zovanie innovacionnyh tekhnologij $v$ razrabotke $i$ realizacii ekonomicheskih reform: sb. st. Mezhdunar. nauch.-prakt. konf. [Collection of Articles of the International Scientific and Practical Conference "The Use of Innovative Technologies in the Development and Implementation of Economic Reforms". Collection of Articles of the International Scientific and Practical Conference]. Magnitogorsk, 2020, pp. 68-70.

Lejbovich A.N. COVID-19 i rynok truda: starye podhody ne rabotayut [COVID-19 and the Labor Market: Old Approaches Don't Work]. Standarty i kachestvo [Standards and Quality], 2020, no. 5, pp. 68-70.

MOT: ofits. sayt Mezhdunarodnoy organizatsii truda (MOT) [Official website of the International
Labour Organization (ILO)]. URL: https:// www.ilo.org/global/lang-en/index.htm (accessed 14 November 2020).

Mizinceva M.F., ed. Pandemiya COVID-2019. Biologiya i ekonomika. Special'nyj vypusk: inform.-analit. sb. [The COVID-2019 Pandemic. Biology and Economics. Special Issue: Information and Analytical Collection]. Moscow, Pero Publ., 2020. 110 p.

Popova A.L., Kanavcev M.V. Transformaciya rossijskogo rynka truda $\mathrm{v}$ usloviyah cifrovizacii ekonomiki [Transformation of the Russian Labor Market in the Conditions of Digitalization of the Economy]. Izvestiya Sankt-Peterburgskogo gosudarstvennogo agrarnogo universiteta [Proceedings of the Saint Petersburg State Agrarian University], 2018. URL: https:// cyberleninka.ru/article/n/transformatsiyarossiyskogo-rynka-truda-v-usloviyahtsifrovizatsii-ekonomiki (accessed 14 November 2020).

Pupysheva R.A., Sitdikov F.F. Ohrana truda v usloviyah pandemii [Labor Protection in the Conditions of a Pandemic]. Studencheskij vestnik [Student Bulletin], 2020, no. 18 (116), pp. 11-13.

Silkina M.L. Problemy rossijskogo rynka truda v usloviyah pandemii [Problems of the Russian Labor Market in the Context of a Pandemic]. Sovremennye tendencii i tekhnologii razvitiya potenciala regionov: sb. st. I Nacional'noj nauch.-prakt. konf., g. Sankt-Peterburg, 24 apr. $2020 \mathrm{~g}$. [Modern Trends and Technologies for the Development of the Potential of Regions. Collection of Articles of the I National Scientific and Practical Conference. Saint Petersburg, April 24, 2020]. Saint Petersburg, 2020, pp. 117-119.

Soldatova S.S., Soldatova V.V. Rossijskij rynok truda v usloviyah narastaniya ekonomicheskogo krizisa vsledstvie pandemii [The Russian Labor Market in the Conditions of the Growing Economic Crisis Due to the Pandemic]. Nauchnoobrazovatel'nyj zhurnal StudNet [Scientific and Educational Journal StudNet], 2020, no. 2, pp. 424-428.

COVID-19: Quarantined Economics. URL: https// www. eulerhermes.com/en_global/ economicresearch/insights/covid-19quarantined-economics.html (accessed 15 November 2020).

Headhunter.ru: ofits. sayt portala [Headhunter.ru. Official Website]. URL: www.hh.ru (accessed 15 November 2020).

JobLab.ru: ofits. sayt portala [JobLab.ru. Official Website]. URL: www.joblab.ru (accessed 15 November 2020). 
McKinsey: ofits. sayt mezhdunarodnoy konsaltingovoy kompanii [McKinsey. Official Website of the International Consulting Company]. URL: https:// www. mckinsey.com/mgi/overview (accessed 15 November 2020).

Rabota.ru: ofits. sayt portala [Rabota.ru. Official Website]. URL: www.rabota.ru (accessed 16 November 2020).

Rodionov A.V., Rodionova O.Yu. The Role of Personnel Potential in the Development of the Labor Market. Obshchestvo, ekonomika, upravlenie,
2019. URL: https://cyberleninka.ru/article/n/therole-of-personnel-potential-in-thedevelopmentof-the-labor-market/viewer (accessed 15 November 2020).

Superjob.ru: ofits. sayt portal [Superjob.ru. Official Website]. URL: superjob.ru (accessed 16 November 2020).

X5 Retail Group: ofits. sayt [X5 Retail Group. Official Website]. URL: https://www.x5.ru/ru/Pages/ Media/News/040620-online.aspx (accessed 15 November 2020).

\section{Information About the Authors}

Maria F. Mizintseva, Doctor of Sciences (Economics), Professor, Director, All-Russian Institute of Scientific and Technical Information of the Russian Academy of Sciences, Usievicha St, 20, 125190 Moscow, Russian Federation, mfmizin@mail.ru, https://orcid.org/0000-0002-1276-2753

Anna R. Sardarian, Candidate of Sciences (Economics), Senior Researcher, Department of Scientific Information on Economics, Finance and Management, All-Russian Institute of Scientific and Technical Information of the Russian Academy of Sciences, Usievicha St, 20, 125190 Moscow, Russian Federation, anna_al_edu@mail.ru, https://orcid.org/0000-0002-7406-3149

\section{Информация об авторах}

Мария Федоровна Мизинцева, доктор экономических наук, профессор, директор, Bceроссийский институт научной и технической информации РАН, ул. Усиевича, 20, 125190 г. Москва, Российская Федерация, mfmizin@mail.ru, https://orcid.org/0000-0002-1276-2753

Анна Романовна Сардарян, кандидат экономических наук, старший научный сотрудник отдела научной информации по экономике и управлению, Всероссийский институт научной и технической информации РАН, ул. Усиевича, 20, 125190 г. Москва, Российская Федерация, anna_al_edu@mail.ru, https://orcid.org/0000-0002-7406-3149 